\title{
The role of self-teaching in learning orthographic and semantic aspects of new words
}

Article

Published Version

Open Access

Ricketts, J., Bishop, D. V., Pimperton, H. and Nation, K. (2011) The role of self-teaching in learning orthographic and semantic aspects of new words. Scientific Studies of Reading, 15 (1). pp. 47-70. ISSN 1088-8438 doi:

https://doi.org/10.1080/10888438.2011.536129 Available at https://centaur.reading.ac.uk/27892/

It is advisable to refer to the publisher's version if you intend to cite from the work. See Guidance on citing.

To link to this article DOI: http://dx.doi.org/10.1080/10888438.2011.536129

Publisher: Routledge

All outputs in CentAUR are protected by Intellectual Property Rights law, including copyright law. Copyright and IPR is retained by the creators or other copyright holders. Terms and conditions for use of this material are defined in the End User Agreement.

www.reading.ac.uk/centaur 
Central Archive at the University of Reading

Reading's research outputs online 
This article was downloaded by: [University of Reading]

On: 30 October 2013, At: 03:28

Publisher: Routledge

Informa Ltd Registered in England and Wales Registered Number: 1072954

Registered office: Mortimer House, 37-41 Mortimer Street, London W1T 3J H, UK

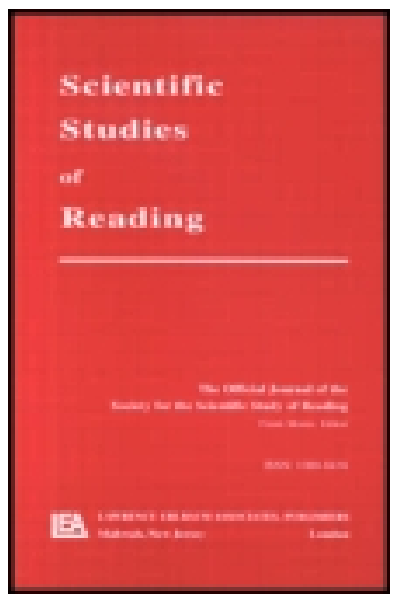

\section{Scientific Studies of Reading}

Publication details, including instructions for authors and subscription information:

http:// www. tandfonline.com/loi/ hssr20

\section{The Role of Self-Teaching in Learning Orthographic and Semantic Aspects of New Words}

Jessie Ricketts ${ }^{a}$, Dorothy V. M. Bishop ${ }^{b}$, Hannah Pimperton ${ }^{b} \&$ Kate Nation ${ }^{b}$

a University of London

${ }^{b}$ University of Oxford

Published online: $18 \mathrm{~J}$ an 2011.

To cite this article: J essie Ricketts, Dorothy V. M. Bishop, Hannah Pimperton $\&$ Kate Nation (2011) The Role of Self-Teaching in Learning Orthographic and Semantic Aspects of New Words, Scientific Studies of Reading, 15:1, 47-70, DOI: $10.1080 / 10888438.2011 .536129$

To link to this article: http:// dx.doi. org/ 10.1080/ 10888438.2011.536129

\section{PLEASE SCROLL DOWN FOR ARTICLE}

Taylor \& Francis makes every effort to ensure the accuracy of all the information (the "Content") contained in the publications on our platform. Taylor \& Francis, our agents, and our licensors make no representations or warranties whatsoever as to the accuracy, completeness, or suitability for any purpose of the Content. Versions of published Taylor \& Francis and Routledge Open articles and Taylor \& Francis and Routledge Open Select articles posted to institutional or subject repositories or any other thirdparty website are without warranty from Taylor \& Francis of any kind, either expressed or implied, including, but not limited to, warranties of merchantability, fitness for a particular purpose, or non-infringement. Any opinions and views expressed in this article are the opinions and views of the authors, and are not the views of or endorsed by Taylor $\&$ Francis. 
The accuracy of the Content should not be relied upon and should be independently verified with primary sources of information. Taylor \& Francis shall not be liable for any losses, actions, claims, proceedings, demands, costs, expenses, damages, and other liabilities whatsoever or howsoever caused arising directly or indirectly in connection with, in relation to or arising out of the use of the Content.

This article may be used for research, teaching, and private study purposes. Any substantial or systematic reproduction, redistribution, reselling, loan, sub-licensing, systematic supply, or distribution in any form to anyone is expressly forbidden. Terms $\&$ Conditions of access and use can be found at http://www.tandfonline.com/page/terms-and-conditions

Taylor \& Francis and Routledge Open articles are normally published under a Creative Commons Attribution License http://creativecommons.org/licenses/ by/3.0/. However, authors may opt to publish under a Creative Commons Attribution-Non-Commercial License http://creativecommons.org/licenses/ by-nc/3.0/ Taylor \& Francis and Routledge Open Select articles are currently published under a license to publish, which is based upon the Creative Commons Attribution-Non-Commercial No-Derivatives License, but allows for text and data mining of work. Authors also have the option of publishing an Open Select article under the Creative Commons Attribution License http:// creativecommons.org/licenses/by/3.0/.

It is essential that you check the license status of any given Open and Open Select article to confirm conditions of access and use. 


\title{
The Role of Self-Teaching in Learning Orthographic and Semantic Aspects of New Words
}

\author{
Jessie Ricketts \\ University of London \\ Dorothy V. M. Bishop, Hannah Pimperton, and Kate Nation \\ University of Oxford
}

\begin{abstract}
This study explores how children learn the meaning (semantics) and spelling patterns (orthography) of novel words encountered in story context. English-speaking children $(N=88)$ aged 7 to 8 years read 8 stories and each story contained 1 novel word repeated 4 times. Semantic cues were provided by the story context such that children could infer the meaning of the word (specific context) or the category that the word belonged to (general context). Following story reading, posttests indicated that children showed reliable semantic and orthographic learning. Decoding was the strongest predictor of orthographic learning, indicating that self-teaching via phonological recoding was important for this aspect of word learning. In contrast, oral vocabulary emerged as the strongest predictor of semantic learning.
\end{abstract}

As children's reading skills develop, the reading process provides an opportunity for them to learn new words (e.g., Beck, Perfetti, \& McKeown, 1982; Nagy, Herman, \& Anderson, 1985). When a new word is encountered in print, a child with basic word reading skills can attempt to translate its written form (orthography) into its spoken form (phonology). This decoding process can form a basis for new visual word forms to be learned (Share, 1995). Further, when an unfamiliar word is read in context, the meaning of this word (lexical-semantics) can often be inferred using information supplied by the surrounding text. Therefore, exposing

Correspondence should be sent to Jessie Ricketts, Department of Psychology and Human Development, Institute of Education, University of London, 25 Woburn Square, London, WC1H OAA, United Kingdom. E-mail: j.ricketts@ioe.ac.uk 
children to novel words in context provides an opportunity for them to learn orthographic and lexical-semantic information, processes we term orthographic and semantic learning, respectively. These aspects of lexical learning have usually been studied separately. Using an adaptation of the self-teaching paradigm (Share, 1999), we investigated the predictors of orthographic and semantic learning in a large group of children aged 7 to 8 years. In particular, we assessed the extent to which phonological recoding (or decoding) during reading predicted each aspect of word learning and explored the hypothesis that distinct component reading and language skills are associated with orthographic and semantic learning.

The self-teaching hypothesis (Share, 1995) provides an account of orthographic learning, its main tenet being that the process of successfully decoding (or phonologically recoding) orthographic strings acts as a self-teaching mechanism so that item-specific orthographic representations can be encoded (for similar theories, see Ehri, 2005; Rack, Hulme, Snowling, \& Wightman, 1994). To test the self-teaching hypothesis, Share (1999) developed an orthographic learning paradigm in which children decoded nonwords in story contexts and orthographic learning was later assessed using naming, spelling, and orthographic choice posttests. The same study also provided support for the self-teaching hypothesis by demonstrating that decoding skill predicted orthographic learning, a finding that has been well replicated (Bowey \& Miller, 2007; Cunningham, 2006; Cunningham, Perry, Stanovich, \& Share, 2002; Kyte \& Johnson, 2006; Nation, Angell, \& Castles, 2007; Share, 1999). After controlling for the variance explained by decoding, indices of existing orthographic knowledge such as performance on orthographic choice tasks also predicted unique variance in orthographic learning (Cunningham, 2006; Cunningham et al., 2002; although see Bowey \& Miller, 2007).

Some decoding attempts may be unsuccessful—if the child has poor decoding skills or the word has a strange spelling and cannot be easily decoded (e.g., a direct translation of yacht would lead to a mispronunciation). In these cases support from the surrounding context can facilitate decoding, allowing the reader to arrive at a feasible pronunciation and encode the orthographic form (cf. Share, 1995). Previous research has shown that word reading is supported by context (Archer \& Bryant, 2001; Nation \& Snowling, 1998). However, context does not appear to facilitate orthographic learning in the self-teaching paradigm; some researchers have found no effect of context (Cunningham, 2006; Nation, Angell, et al., 2007; Ricketts, Bishop, \& Nation, 2008) and others have reported reduced orthographic learning for items learned in context in relation to items learned in isolation (Landi, Perfetti, Bolger, Dunlap, \& Foorman, 2006; Stuart, Masterson, \& Dixon, 2000).

Although these studies have focused on the learning of orthographic patterns, the reading process also provides an opportunity for children to learn the meaning of novel phonological forms. It is well established that when unknown words 
are encountered in supportive context readers can, and do, use semantic, syntactic, and/or pragmatic information from the text to learn the meaning of new words (e.g., Cain, Oakhill, \& Elbro, 2003; Nagy et al., 1985). It seems reasonable to assume that the amount of learning that occurs will be associated with the ability to broadly understand the texts. Indeed, individual differences in children's reading comprehension skills predict how well they learn the meanings of new words from context. For example, Swanborn and de Glopper (2002) showed that in a group of 223 children, participants with low reading comprehension scores learned fewer words from context than peers with high comprehension scores. This finding is consistent with data showing that poor comprehenderschildren who have reading comprehension impairments despite the ability to read words and texts at an age-appropriate level-are poor at inferring the meaning of new words from context (Cain et al., 2003; Cain, Oakhill, \& Lemmon, 2004; Oakhill, 1983) and remembering them over time (Nation, Snowling, \& Clarke, 2007; Ricketts et al., 2008; for a similar finding with adults see Perfetti, Wlotko, \& Hart, 2005).

Reading experience enables vocabulary development, with measures of print exposure predicting vocabulary growth (e.g., Echols, West, Stanovich, \& Zehr, 1996). Equally though, existing vocabulary knowledge is a significant predictor of semantic learning following reading (e.g., Cain et al., 2004; Ewers \& Brownson, 1999; Sénéchal, Thomas, \& Monker, 1995; Shefelbine, 1990). Cain et al. (2004) found that the ability to infer word meanings from context was predicted by both oral vocabulary and reading comprehension but that reading comprehension emerged as the stronger predictor. One explanation for the relationship between existing vocabulary knowledge and new word learning put forward by Cain et al. was that the link is mediated by the ability to employ inference strategies. A related proposal is that the relationship may be indirect such that knowledge of vocabulary is what supports comprehension-the formation of a rich and coherent representations of texts - and that this in turn supports inference of new word meanings.

In addition to vocabulary and reading comprehension, we anticipated that reading accuracy would predict semantic learning because in the present learning task, new words are encountered in connected text. Therefore, the ability to use context to infer the semantic properties of a new word will be determined, to some extent at least, by the ability to read and access the surrounding text.

Studies that have employed self-teaching paradigms have not probed learning for new word meanings, instead focusing on orthographic learning. Orthographic learning is typically measured after the reading of connected text but without assessing semantic learning directly. Therefore, sensitivity to the semantic information conveyed by the context cannot be determined. Just as orthographic learning studies have neglected to measure semantic learning, many studies investigating semantic learning have not reported concurrent measures of orthographic 
learning (for exceptions, see Clay, Bowers, Davis, \& Hanley, 2007; Ricketts et al., 2008; Ricketts, Bishop, \& Nation, 2009; Rosenthal \& Ehri, 2008). In the present study we measured both orthographic and semantic learning across the same participants and items, enabling us to examine the acquisition of representations that include phonological, semantic, and orthographic information and are thus more complex and of "higher lexical quality" (cf. Perfetti \& Hart, 2002) than the phonological-semantic or phonological-orthographic mappings learned in other paradigms. Further, this design allowed us to compare each aspect of learning.

One study that has investigated both orthographic and semantic learning of novel words was conducted by Ricketts et al. (2008). Poor comprehenders aged 9 to 10 years were matched to skilled comprehender controls for chronological age, nonverbal reasoning, and decoding, but groups differed significantly on measures of reading comprehension and oral vocabulary knowledge. Poor and skilled comprehenders showed equivalent levels of orthographic learning, but the poor comprehenders showed poorer retention of semantic information. Therefore, beyond decoding, reading comprehension and oral vocabulary were related to semantic learning but not orthographic learning. However, a recent study challenges this conclusion. Ouellette and Fraser (2009) found that in 9-year-old children, performance on a standardized oral vocabulary task predicted orthographic learning after controlling for the variance explained by decoding. It is worth noting that the Ricketts et al. study included children with age-appropriate or above decoding skills alongside either poor or good reading comprehension. One aim of the present study was to investigate predictors of orthographic and semantic aspects of word learning in a large group of unselected children.

In the present study, we sought to probe word learning using an adapted version of Share's (1999) self-teaching paradigm. Children were exposed to eight nonwords, each embedded in its own story context. Children read the eight stories aloud; four of these provided cues to exact nonword meaning, and four provided only ambiguous cues. Contextual constraint was manipulated to assess the ability to use context to infer the meaning of new words. After reading stories aloud, children completed three posttests; an orthographic choice task and a spelling task were used to assess learning of spelling patterns (orthographic learning), and a nonword-picture matching task was used to probe children's ability to infer the meaning of words from story context (semantic learning). Standardized measures of reading and existing oral vocabulary knowledge were administered alongside the experiment to investigate these variables as predictors of orthographic and semantic aspects of word learning.

This design allowed us to explore predictors of orthographic and semantic aspects of word learning for the same items in a large group of unselected children and address the following set of hypotheses. First, evidence that decoding 
skills predict orthographic learning (Bowey \& Miller, 2007; Cunningham, 2006; Cunningham et al., 2002; Kyte \& Johnson, 2006; Nation, Angell, et al., 2007; Share, 1999) led to the hypothesis that individual differences in the ability to decode nonwords would be associated with orthographic learning performance. However, it was expected that existing orthographic knowledge (as indexed by word reading ability) might emerge as a stronger predictor of orthographic learning (Cunningham, 2006; Cunningham et al., 2002). Second, given that reading is a central part of the learning paradigm, we hypothesized that reading accuracy would predict semantic as well as orthographic learning. Third, on the basis of previous studies (Cain et al., 2003; Cain et al., 2004; Oakhill, 1983) it was anticipated that individual differences in reading comprehension and vocabulary would be associated with semantic learning performance. However, this was tempered by a previous finding (Ricketts et al., 2008) that poor reading comprehension was not associated with poor semantic learning immediately after exposure to nonwords in context. Finally, we sought to investigate whether existing vocabulary knowledge would be associated with orthographic learning (Ouellette \& Fraser, 2009) or not (Ricketts et al., 2008).

\section{METHOD}

\section{Participants}

Eighty-eight children (35 boys, 53 girls) participated in this study. Children ranged in age from 7.67 to 8.75 years $(M=8.24, S D=.28)$ and attended seven schools serving socially mixed catchment areas in Oxford. All spoke English as a first language, and no child had any recognized special educational need.

\section{Materials and Procedure}

Children were seen for two sessions on different days, each session lasting approximately $30 \mathrm{~min}$ to $1 \mathrm{hr}$. In the first session children completed background measures of reading, language, and general cognitive abilities. In the second session children completed the word learning experiment.

\section{Background Measures}

Reading. Word and nonword reading skills were assessed using the Test of Word Reading Efficiency (TOWRE; Torgesen, Wagner, \& Rashotte, 1999). Text reading accuracy and reading comprehension were assessed by the Neale Analysis of Reading Ability-II (Neale, 1997). In the Neale Analysis of Reading Ability-II, children read aloud passages of connected text and then answer comprehension questions relating to each passage. 
Vocabulary. This was measured using the Vocabulary subtest of the Wechsler Abbreviated Scale of Intelligence (Wechsler, 1999), in which children are asked to verbally define words.

Nonverbal reasoning. This was measured using a pattern completion task-the Matrix Reasoning subtest of the Wechsler Abbreviated Scale of Intelligence (Wechsler, 1999).

\section{Word Learning Experiment}

Children were exposed to eight nonwords embedded in story contexts. A story was constructed for each nonword in which it was repeated four times. Context was manipulated such that half of the stories provided specific cues to the meaning of the nonword (specific condition) and half provided ambiguous cues (general condition). After the exposure phase, children completed an unrelated filler task followed by three posttests in the following order: orthographic choice and spelling to assess orthographic learning, and nonword-picture matching to assess semantic learning.

Stimuli. The stimuli used in this experiment are presented in the appendix. Eight pairs of four-letter homophonic nonwords were selected from Bowey and Muller (2005; see also Nation, Angell, et al., 2007). These items were selected as their homophonic status conforms to British English pronunciation. Two pairs represented each of four vowel sounds. One item from each pair was selected to be used as a target, and the other was used as a homophone foil in the orthographic choice posttest. For each vowel sound, both spelling patterns appeared in the target and foil sets. This was done to control for any bias that might result from one spelling being more frequently used to represent the phoneme (i.e., more consistent) than the other. Bowey and Muller did not report a measure of sound-to-spelling consistency for their stimuli. However, data from the Children's Printed Word Database (Masterson, Stuart, Dixon, \& Lovejoy, 2010) confirmed that consistency was roughly equivalent across the two spelling patterns for each vowel (see appendix). This consistency rating reflects the frequency with which a particular phoneme is represented by a grapheme in monosyllabic words in children's literature. ${ }^{1}$

\footnotetext{
${ }^{1}$ We thank an anonymous reviewer for noting that the consistency ratings were less similar for the vowel sounds in nawn/lork and ferd/surn. Orthographic choice and spelling was equivalent for nawn and lork and spelling was equivalent for ferd and surn. However, children were significantly less likely to correctly select nawn than lork in the orthographic choice task, providing some evidence of reduced orthographic learning for the less consistent spelling-sound mapping in nawn, but only in a task where the more consistent homophone (norn) was presented as a distracter.
} 
Nonwords were assigned a referent/meaning analogous to a word that children would know. Each referent represented a relatively high-frequency item (e.g., giraffe) from one of eight familiar categories (e.g., animal). Referents were generated by asking 13 adults to list five items in each category. We chose items that were frequently generated but not the most frequent to ensure that children would know the items but that they would not be overly salient.

Exposure to nonwords in story context. Children were told that they would be learning about a "foreign" girl called Vindy and her favorite things. They then read eight stories, one for each nonword. Each story had five sentences, four of which contained one mention of the nonword. Thus children were exposed to each nonword a total of four times. Two stories were constructed for each nonword to manipulate the specificity of the contextual information. One version (the general context condition) indicated the category that the nonword belonged to (e.g., an animal). The alternative version (specific context condition) differed only in terms of one critical sentence, which gave cues to the exact meaning of the nonword (e.g., giraffe). A sentence at the beginning of each story always indicated the object category, and the critical sentence always appeared in the middle of the story. Specific and general versions of each story were developed using a cloze procedure. This ensured that nonword meanings were highly predictable in the specific context but minimally predictable in the general context. Specific and general texts were matched for number of words and readability. In an additional pilot stage, children were asked to read the texts (with nonwords replaced with their referent labels) to ensure that all of the words could be easily read by children of this age.

During the exposure phase of the experiment, each child read four general stories and four specific stories. To counterbalance across context half of the children read the general version of half of the stories and the specific version of the other stories. The remaining children received the opposite. This also resulted in a paradigm in which children read nonwords that shared the same vowel sound in different context conditions (e.g., nawn in general condition and lork in specific condition). Stories were presented one at a time on a computer screen, and the order of presentation was randomized by the E-Prime program (Schneider, Eschman, \& Zuccolotto, 2002a, 2002b). Children were given online feedback (correct pronunciation) for any words or nonwords read incorrectly. This exposure phase yielded a measure of the number of words and nonword targets read correctly.

Orthographic learning posttests. Two posttests assessed orthographic learning. Children first completed an orthographic choice task in which they had to select the target spelling from an array of four letter strings using a key press. The target (e.g., lork) was presented with three distracters, the (British 
English) homophonic spelling (lawk) and two orthographic distracters that were constructed by replacing the final consonant in the target (lort) and homophone (lawt). Homophone distracters are presented alongside targets in the appendix. On each trial, one letter string appeared in each corner of a computer screen and target position was counterbalanced such that targets were equally likely to appear in each quadrant. Children were instructed to press a key to indicate which word they'd seen before. To ensure that they understood the demands of the task, a practice trial was completed first and then experimental trials were presented in a random order. The second orthographic learning posttest required children to spell each nonword to dictation. Children were provided with a pen and paper to complete the task, and an item was scored as correct if children produced the intended spelling exactly (all letters in the correct order). Orthographic choice and spelling accuracy scores (proportion correct) were recorded for each child.

Semantic learning posttest. A nonword-picture matching task assessed semantic learning. In each trial a nonword spelling (e.g., lork) was presented in the center of a computer screen with an array of four pictures, one in each corner. A picture of the target (giraffe) was presented with three distracters. The category distracter corresponded to another object from the same category (lion), the story distracter was relevant to the story that the target was embedded in (zookeeper), and the unrelated distracter was a nontarget object from one of the other categories (chips). Target position was counterbalanced such that the target appeared in each corner an equal number of times. Children were asked to indicate the meaning of each nonword using a key press. A practice trial was presented and then experimental trials were completed in a random order. Accuracy (proportion correct) was recorded for each child.

\section{RESULTS}

\section{Background Measures}

The top portion of Table 1 summarizes performance on background measures of reading, language, and nonverbal reasoning skills. Mean scores were close to population norms on most measures, with scores on measures of oral vocabulary and reading comprehension falling in the lower average range.

\section{Word Learning Experiment}

\section{Exposure Phase}

While reading the stories, children read words accurately $(M$ words correct $=.97$, $S D=.05$ ) confirming that the texts were at an appropriate reading level. During 
TABLE 1

Summary of Performance on Background Measures and Experiment Posttests

\begin{tabular}{|c|c|c|c|}
\hline Measure & $M$ & $S D$ & Range \\
\hline \multicolumn{4}{|l|}{ Background measures } \\
\hline Nonverbal reasoning ${ }^{\mathrm{a}}$ & 53.39 & 8.81 & $36-70$ \\
\hline Vocabulary $^{\mathrm{a}}$ & 45.89 & 11.85 & $22-73$ \\
\hline Decoding $^{\mathrm{b}}$ & 100.63 & 14.40 & $72-132$ \\
\hline Word reading ${ }^{\mathrm{b}}$ & 101.28 & 14.59 & $61-128$ \\
\hline Text reading accuracy ${ }^{\mathrm{b}}$ & 98.44 & 12.07 & $70-130$ \\
\hline Reading comprehension ${ }^{\mathrm{b}}$ & 91.75 & 10.87 & $74-130$ \\
\hline \multicolumn{4}{|l|}{ Posttests } \\
\hline Orthographic choice-general condition $^{\mathrm{c}}$ & .63 & .29 & $.00-1.00$ \\
\hline Orthographic choice- - specific condition ${ }^{\mathrm{c}}$ & .64 & .27 & $.00-1.00$ \\
\hline Orthographic choice-overall ${ }^{c}$ & .63 & .20 & $.13-1.00$ \\
\hline Spelling—general condition ${ }^{\mathrm{c}}$ & .55 & .31 & $.00-1.00$ \\
\hline Spelling-specific condition ${ }^{\mathrm{c}}$ & .51 & .32 & $.00-1.00$ \\
\hline Spelling-overall ${ }^{\mathrm{c}}$ & .53 & .26 & $.00-1.00$ \\
\hline Nonword-picture matching—general condition ${ }^{\mathrm{c}}$ & .22 & .20 & $.00-.75$ \\
\hline Nonword-picture matching-specific condition ${ }^{\mathrm{c}}$ & .57 & .27 & $.00-100$ \\
\hline Nonword-picture matching_-overall ${ }^{\mathrm{c}}$ & .40 & .18 & $.13-.75$ \\
\hline
\end{tabular}

${ }^{\mathrm{a}} T$ scores, $M=50, S D=10 .{ }^{\mathrm{b}}$ Standard scores, $M=100, S D=15 .{ }^{\mathrm{c}}$ Proportion correct.

this exposure phase, nonwords were also read with a high degree of accuracy at the first $(M=.67, S D=.35)$, second $(M=.93, S D=.17)$, third $(M=.87$, $S D=.23)$, and fourth $(M=.94, S D=.14)$ attempt, and overall $(M=.85$, $S D=.20)$. This indicates that children read a large proportion of the nonwords correctly and were learning orthography-phonology mappings online, with performance increasing to near ceiling levels by the fourth attempt. Having established that high performance in the exposure phase provided an opportunity for learning to occur, the effect of context on learning is considered next, followed by regression analyses to explore predictors of orthographic and semantic learning.

\section{Orthographic and Semantic Posttests}

The bottom portion of Table 1 summarizes performance on orthographic and semantic learning posttests. Overall performance in the orthographic posttests indicated that children recognized and produced more than half of the items correctly. To investigate the effect of context on orthographic learning, one-way analyses of variance (ANOVAs) with context condition as a related samples factor (general vs. specific) were conducted by subjects $\left(F_{s}\right)$ and by items $\left(F_{i}\right)$. Context condition did not have a significant effect on orthographic choice or spelling ( $F$ values by subjects and by items $\leq 1, p s>.05$ ). For semantic learning, 
a one-way ANOVA with context as a related samples factor (general vs. specific) showed that nonword-picture matching accuracy was significantly higher in the specific than general condition, $F_{s}(1,87)=117.49, p<.001, \eta^{2}=.58 ; F_{i}(1$, 14) $=42.68, p<.001, \eta^{2}=.75$.

As shown in Table 1, semantic learning performance was low in the general condition. To investigate this further, error patterns were inspected. Three distracters were presented alongside the target in the semantic learning task: a category distracter, a story distracter, and an unrelated distracter. The semantic relationship between the target and distracters varied in a graded manner, allowing for systematic investigation of sensitivity to semantic information. Figure 1 summarizes the proportion of targets and distracters that children selected across general and specific context conditions. In both conditions children selected few unrelated distracters. In the specific condition, children were selecting a larger number of targets than category and story distracters, indicating that they were sensitive to the target-specific cues in the text. In the general condition, appropriate semantic learning is indicated by the selection of both targets and category distracters because contextual cues indicated the category that the target belonged to. Figure 1 suggests that although both targets and category distracters were selected, children were approximately twice as likely to select category distracters as targets. This raises the possibility that category distracters were more salient objects than targets.

An adjusted semantic learning measure was calculated to take error patterns into account. Children were assigned a score of 1 if they selected the target in the specific condition and a score of 1 if they selected either the target or the category distracter in the general condition $(M$ proportion correct for this measure $=.62$, $S D=.22$ ). The adjusted semantic learning score (rather than the raw semantic

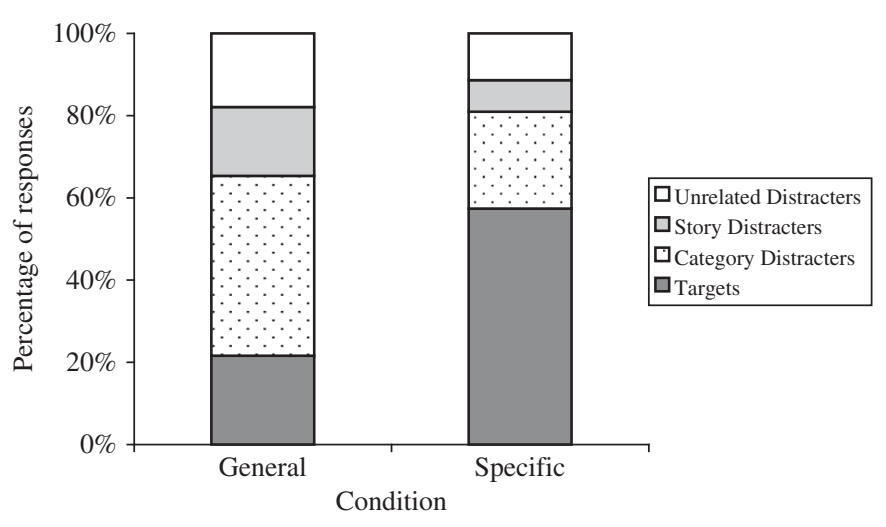

FIGURE 1 Percentage of responses made during semantic learning posttest. 
learning score) was used in all further analyses as it was deemed a better index of overall sensitivity to semantic information. ${ }^{2}$

\section{Predicting Orthographic and Semantic Aspects of Word Learning}

A series of hierarchical regressions were conducted to address our hypotheses, namely that decoding and reading accuracy would predict orthographic learning, reading accuracy, reading comprehension, and oral vocabulary knowledge would predict semantic learning and oral vocabulary might predict orthographic learning. Correlation coefficients are presented in Table 2. Inspection of the distribution of scores suggested some departure from the normal distribution. Therefore, the more conservative Spearman's rho coefficients are reported. Orthographic learning was highly correlated with measures of decoding, word reading, and text reading accuracy, whereas weaker correlations were observed with reading comprehension, vocabulary, and nonverbal reasoning. The adjusted semantic learning score was significantly and positively correlated with target decoding, text reading accuracy, reading comprehension, vocabulary, and all other background measures.

Hierarchical regression analyses were conducted with orthographic choice and spelling accuracy as outcome variables for orthographic learning and the adjusted semantic learning score as the outcome variable for semantic learning. Although the distribution of raw data was not strictly normal in all cases, inspection of diagnostic tests and residuals for each regression model suggested that the necessary assumptions for regression models were met (Field, 2005). Regression models predicting orthographic learning will be considered first, shown in Table 3. Three-step hierarchical regressions investigated the relative predictive power of background measures of decoding, word reading, text reading accuracy, reading comprehension, and vocabulary after controlling for the variance explained by nonverbal reasoning and target decoding during story reading. Nonverbal reasoning and target decoding scores were entered into each model at the first and second steps, respectively, and background measures were entered into separate regression models at the third step. Table 3 summarizes these analyses, reporting the change in $R^{2}$ and associated $p$ value for each step. Table 3 also includes standardized $\beta$ values for predictors; these values correspond to the variable in a complete model with the three relevant variables included.

At Steps 1 and 2, nonverbal reasoning explained significant variance in orthographic choice (but not spelling) and target decoding explained significant unique variance in both orthographic learning measures. After controlling for these

\footnotetext{
${ }^{2}$ Given the effect of context on semantic learning, a contextual facilitation score was also calculated using log odds to account for floor and ceiling effects (cf. Allerup \& Elbro, 1998). However, because this measure was not significantly correlated with any of the predictors, it was not considered further.
} 


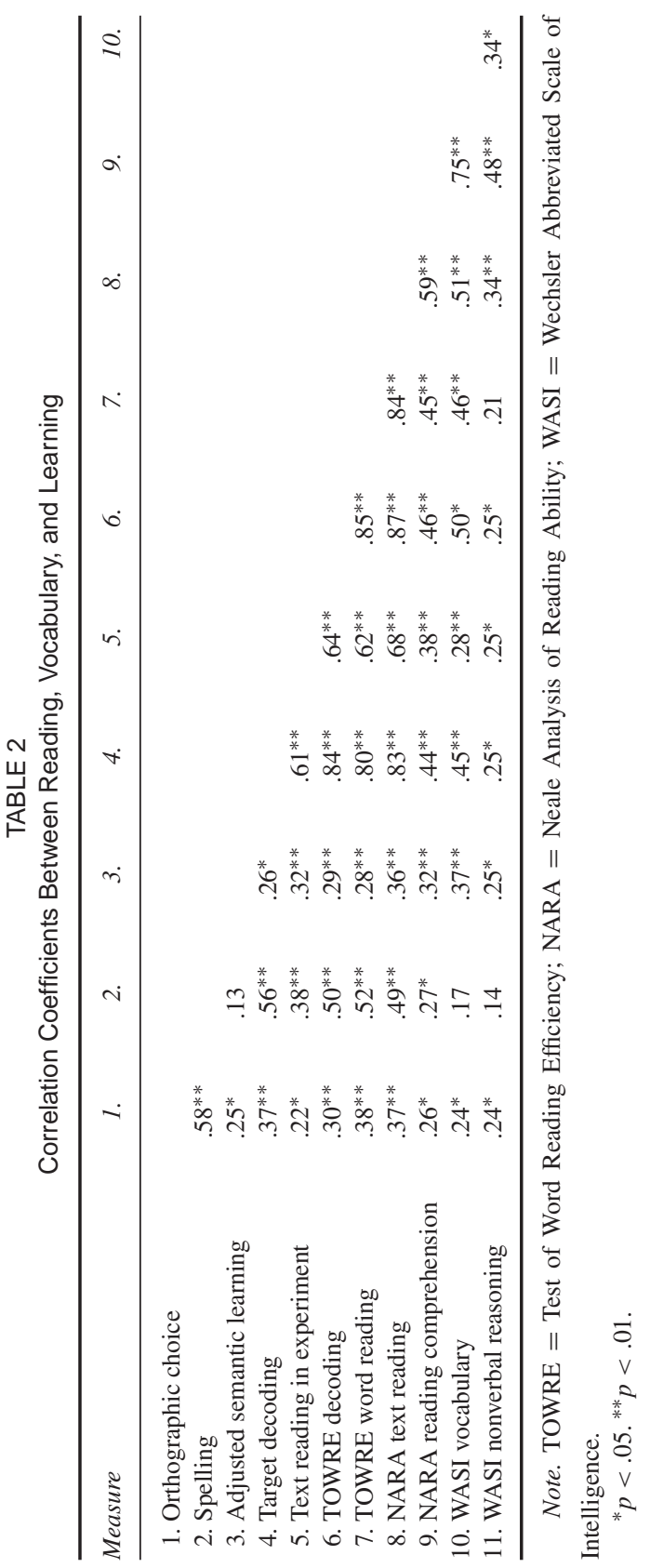




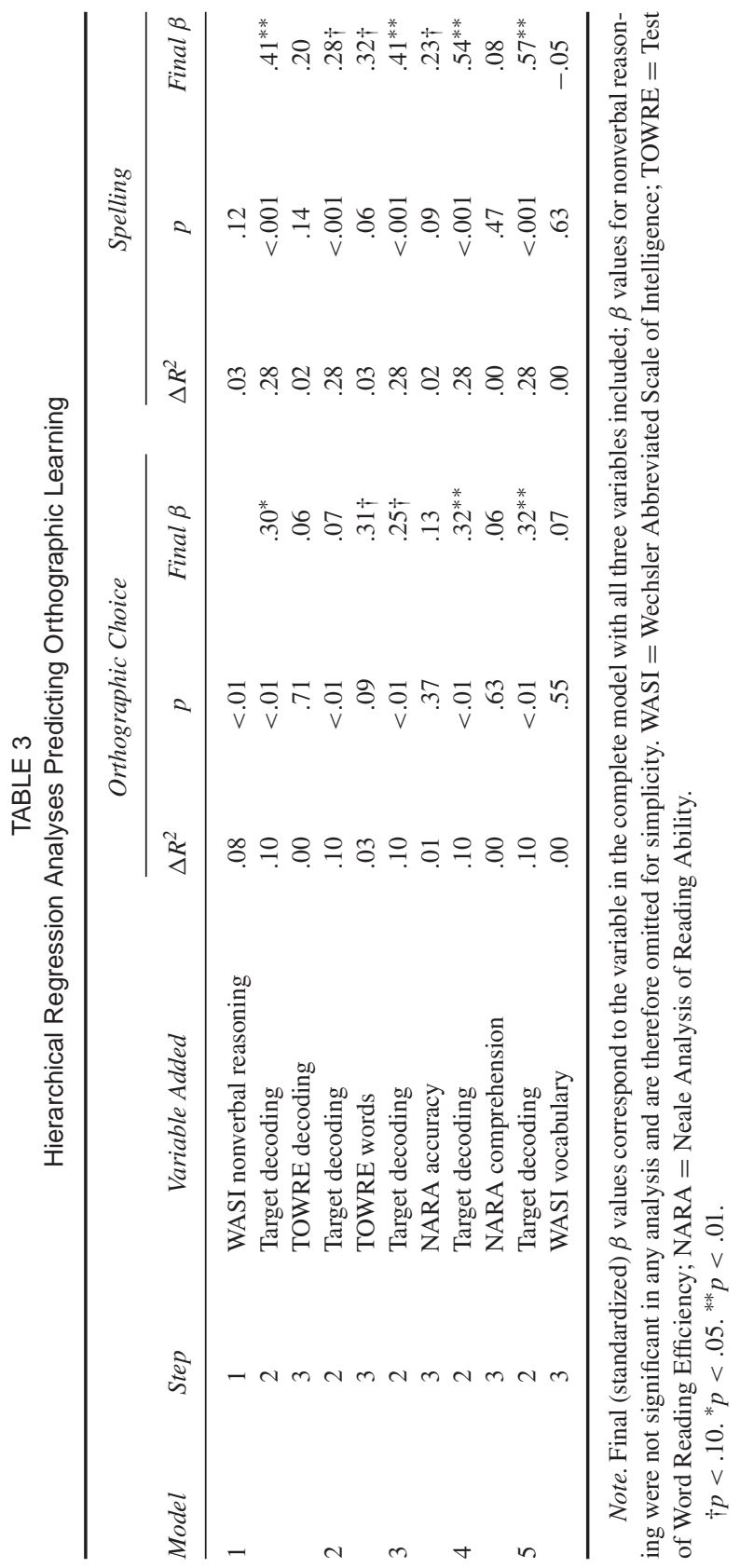


TABLE 4

Hierarchical Regression Analyses Predicting Semantic Learning

\begin{tabular}{|c|c|c|c|c|c|}
\hline Model & Step & Variable Added & $\Delta R^{2}$ & $p$ & Final $\beta$ \\
\hline \multicolumn{6}{|c|}{ Three-step models } \\
\hline \multirow[t]{3}{*}{1} & 1 & WASI nonverbal reasoning & .07 & .01 & \\
\hline & 2 & Target decoding & .03 & .07 & .03 \\
\hline & 3 & TOWRE decoding & .02 & .14 & .22 \\
\hline \multirow[t]{2}{*}{2} & 2 & Target decoding & .03 & .07 & .00 \\
\hline & 3 & TOWRE words & .01 & .25 & .22 \\
\hline \multirow[t]{2}{*}{3} & 2 & Target decoding & .03 & .07 & -.03 \\
\hline & 3 & NARA accuracy & .05 & .02 & $.34^{*}$ \\
\hline \multirow[t]{2}{*}{4} & 2 & Target decoding & .03 & .07 & .14 \\
\hline & 3 & NARA comprehension & .03 & .12 & .19 \\
\hline \multirow[t]{2}{*}{5} & 2 & Target decoding & .03 & .07 & .11 \\
\hline & 3 & WASI vocabulary & .06 & .01 & $.28^{*}$ \\
\hline \multicolumn{6}{|c|}{ Four-step models } \\
\hline \multirow[t]{4}{*}{6} & 1 & WASI nonverbal reasoning & .07 & .01 & \\
\hline & 2 & Target decoding & .03 & .07 & -.03 \\
\hline & 3 & WASI vocabulary & .06 & .01 & $.22 \dagger$ \\
\hline & 4 & NARA accuracy & .02 & .13 & .24 \\
\hline \multirow[t]{2}{*}{7} & 3 & NARA accuracy & .05 & .02 & .24 \\
\hline & 4 & WASI vocabulary & .03 & .07 & $.22 \dagger$ \\
\hline
\end{tabular}

Note. Final (standardized) $\beta$ values correspond to the variable in the complete model with all three variables included; $\beta$ values for nonverbal reasoning were not significant in any analysis and are therefore omitted for simplicity. WASI $=$ Wechsler Abbreviated Scale of Intelligence; TOWRE $=$ Test of Word Reading Efficiency; NARA = Neale Analysis of Reading Ability.

$\dagger p<.10 .{ }^{*} p<.05$.

variables, the other background measures were not significant predictors of orthographic learning at Step 3. However, but there were trends for word reading to explain significant additional variance in all indices of orthographic learning and for text reading accuracy to explain significant additional variance in spelling.

Table 4 summarizes hierarchical regression models predicting semantic learning and reports the change in $R^{2}$ and associated $p$ value for each step along with standardized $\beta$ values as before. The three-step models were conducted in the same way as the three-step models described for orthographic learning. Table 4 shows that at Step 1, nonverbal reasoning explained significant variance in semantic learning and at Step 2, there was a trend for target decoding to be a significant predictor. After controlling for the variance explained by these variables, text reading accuracy and oral vocabulary explained significant additional variance in semantic learning, whereas nonword reading, word reading and reading comprehension were not significant predictors. Two final regression analyses were conducted to explore the relative predictive power of oral vocabulary and text reading accuracy and these four-step hierarchical regressions are also summarized 
in Table 4. After controlling for the variance explained by nonverbal reasoning, target decoding, and oral vocabulary, text reading accuracy was not a significant predictor of semantic learning. In contrast, there was a trend for oral vocabulary to explain significant variance at Step 4 even after controlling for nonverbal reasoning, target decoding, and text reading accuracy. Although text reading accuracy and oral vocabulary explain similar amounts of variance, oral vocabulary emerged as the strongest predictor.

In summary, target decoding during the exposure phase was the strongest predictor of orthographic learning (cf. Share, 1995). Once nonverbal reasoning and target decoding had been controlled, semantic learning was predicted by independent measures of oral vocabulary and text reading accuracy — whereas these measures explained similar amounts of variance in semantic learning, oral vocabulary was a marginally stronger predictor. It should be noted that although these regression models explain a relatively small amount of the variance in learning, they nevertheless demonstrate that individual differences in orthographic and semantic aspects of learning are predicted by different variables.

\section{DISCUSSION}

Orthographic learning and semantic learning have typically been investigated separately. Previous research has indicated that although orthographic learning is parasitic on phonological decoding, semantic learning is associated with reading comprehension and oral vocabulary knowledge. We aimed to bring together the research on semantic and orthographic learning by using an adaptation of the self-teaching paradigm (Share, 1999) to explore both aspects of word learning following nonword reading in context. We also extended previous studies by investigating predictors of word learning in a large $(N=88)$ unselected group of children aged 7 to 8 years, who showed great variation in performance on the background measures (see Table 1). Participants read eight stories that each contained four repetitions of a nonword. To manipulate contextual constraint, each child read four stories that provided cues to the exact meaning of the nonword (specific context condition) and four stories that cued the category that the nonword belonged to (general context condition). Stories were read with a high degree of accuracy and afterward orthographic learning was assessed using orthographic choice and spelling tasks and semantic learning was assessed using a nonword-picture matching task. The results from these posttests are discussed in turn.

The orthographic learning posttests indicated that word-specific orthographic representations were correctly recognized or produced in more than half of the responses. Correlation and regression analyses showed that target decoding during story reading was associated with each index of orthographic learning. Also, 
orthographic learning was associated with decoding as measured by an independent standardized test of nonword reading (TOWRE; Torgesen et al., 1999). This replicates a number of previous studies (Bowey \& Miller, 2007; Cunningham, 2006; Cunningham et al., 2002; Kyte \& Johnson, 2006; Nation, Angell, et al., 2007; Share, 1999) and is consistent with the self-teaching hypothesis, which assumes that orthographic learning occurs as a result of successful decoding attempts (Share, 1995).

Although self-teaching via decoding might be one mechanism by which children learn orthography, factors beyond decoding may also be important. This study provided some evidence that existing orthographic knowledge contributes to orthographic learning. There were trends for word reading as measured by the TOWRE to be a unique predictor of orthographic choice and spelling performance. This converges with previous studies that have found orthographicprocessing skill to be a predictor of orthographic learning above and beyond decoding (Cunningham, 2006; Cunningham et al., 2002; although see Bowey \& Miller, 2007).

Pacton, Perruchet, Fayol, and Cleeremans (2001) proposed that an implicit associative learning mechanism supports orthographic learning and highlighted the importance of knowledge about orthographic constraints in the development of the orthographic system. Consistent with this, children show superior learning for items with spelling patterns that adhere more closely to the orthographic rules in their language (e.g., Apel, Wolter, \& Masterson, 2006; Wright \& Ehri, 2007). As discussed by Apel (2009), knowledge of orthographic regularities may support the acquisition of novel orthographic information by freeing up memory resources. Taken together, the evidence confers a role for existing orthographic knowledge in orthographic learning. However, it is also likely that orthographic learning episodes will provide an opportunity for orthographic knowledge to be acquired. In support of this, Hulme, Goetz, Gooch, Adams, \& Snowling (2007) found that learning of links between phonology and orthography in a paired-associate learning task predicted orthographic processing (as measured by exception word reading) above and beyond decoding (see also Apel et al., 2006). In sum, this suggests that orthographic learning and existing orthographic knowledge are inextricably linked in development.

In the initial formulation of the self-teaching hypothesis Share (1995) suggested that decoding attempts might be supplemented by support from context, particularly when children are learning items with inconsistent spelling-sound mappings. In this study items were inconsistent to the extent that they contained vowels sounds that can correspond to more than one grapheme in English. Nevertheless, the context condition during story reading did not have an effect on orthographic learning. This is consistent with previous orthographic learning studies that have manipulated context in a similar way (Ricketts et al., 2008), have made comparisons between exposure in isolation and exposure in context (Nation, Angell, et al., 2007) or have investigated word learning after reading cohesive 
versus scrambled passages (Cunningham, 2006). However, in some cases reduced orthographic learning has been observed for items learned in context in relation to items learned in isolation (Landi et al., 2006; Stuart, Masterson, \& Dixon, 2000). It is worth noting that reading in isolation and reading in context place very different reading and language demands on a child whereas the demands in this study were relatively constant across context conditions. Also, only one study has systematically manipulated consistency (Ricketts et al., 2008) and found no effect of context. Taken together, the evidence is broadly consistent with a view that although context may facilitate reading of inconsistent items (Archer \& Bryant, 2001; Nation \& Snowling, 1998), it does not promote learning.

In this experiment, contexts differed in the semantic information that was conveyed in one sentence (although there may have been subtle syntactic differences). Existing semantic knowledge (as indexed by performance on an expressive vocabulary task) was correlated with orthographic choice. However, after controlling for nonverbal reasoning and target decoding in hierarchical regression analyses, oral vocabulary did not explain significant additional variance in orthographic learning. In line with the findings for context, it appears that although oral vocabulary predicts reading of inconsistent words (e.g., Ouellette \& Beers, 2010; for a review see Share, 2008), it does not predict orthographic learning for inconsistent monosyllables. This is at odds with theory and research that confers a role for lexical or semantic knowledge in orthographic processing (reading or learning), especially in the case of items with inconsistent spelling-sound mappings (e.g., Keenan \& Betjemann, 2007; Nation \& Snowling, 2004; Perfetti \& Hart, 2002; Plaut, McClelland, Seidenberg, \& Patterson, 1996; Share, 1995, 2008).

The conclusion that neither context nor semantic knowledge relates to orthographic learning for inconsistent items may be premature given difficulties defining inconsistency and further investigation of this issue is warranted (for a fuller discussion of this issue, see Ricketts et al., 2008). Nonetheless, there is a clear discrepancy between the present findings and those of a study that explored orthographic learning for very similar monosyllabic nonwords in a group of English-speaking children of a similar age. Ouellette and Fraser (2009) reported that performance on a receptive vocabulary task predicted orthographic learning (orthographic choice and spelling) above and beyond decoding. It is worth noting that although we used target word decoding as a control variable in regression analyses (see also Cunningham et al., 2002), Ouellette and Fraser (2009) used performance on an independent measure of decoding — nonword reading as measured by a standardized test. We also included nonverbal reasoning at the first step. In light of this, we reran the regression analyses reported in Table 3 without nonverbal reasoning and replacing target decoding with performance on our independent measure of nonword reading (TOWRE). Again, oral vocabulary did not explain significant additional variance in orthographic choice or spelling performance (all $F$ values $<1$ for this step). The studies also differed in the type of oral vocabulary knowledge task (expressive vs. receptive) and learning paradigm (reading 
in context vs. a direct instruction approach) used. However, it is not clear how these methodological differences could explain the inconsistent findings. Given the small number of studies that have addressed this issue, replication is needed and future research should aim to examine the conditions under which existing semantic knowledge predicts orthographic learning.

Before moving on to consider semantic learning, it is worth noting a more general issue relating to the role of context and semantic knowledge in word-level reading. The English language contains numerous inconsistent or irregular words and its orthographic structure is therefore relatively opaque. Given that context and semantic knowledge are proposed to play a particularly important role in learning and reading inconsistent words, these variables may be of practical importance for the instruction of children learning to read in English, and of theoretical importance for models of reading in English. However, as discussed by Share (2008), the English orthography is an "outlier" in contrast to the majority of natural languages, which have highly consistent or transparent mappings between spelling and sound. Although it is clear that orthographic learning via self-teaching occurs across transparent and opaque languages, and that target decoding is a strong predictor of orthographic learning across languages, it might be that the role of semantic knowledge will differ depending on orthographic transparency.

Returning to our results, in contrast to the orthographic learning findings, both the contextual manipulation and oral vocabulary scores influenced semantic learning. There was a main effect of context condition on semantic learning performance. In line with previous work (Ricketts et al., 2008), this suggests that children were faster and more likely to select targets when the context provided more specific information about the target's identity. Inspection of the error patterns suggested that children selected few unrelated distracters, indicating that in most cases some semantic information was encoded. In the general condition both targets and category distracters were appropriate responses. However, in this condition category distracters were selected approximately twice as often as targets, suggesting that category distracters were more salient than targets. When objects were assigned to nonwords, an effort was made not to use the most salient items in a category. This was done to minimize the likelihood that children would select the target as a result of guessing. The high number of category distracter responses suggests that in future research, more care should be taken to control for the saliency of distracters. For example, pilot data could be collected to ensure that targets and distracters are equally representative exemplars for a particular category and the experiment could be counterbalanced across participants such that objects appear as targets and distracters for different children. ${ }^{3}$

\footnotetext{
${ }^{3}$ We thank an anonymous reviewer for noting that the category distracter used in the nonwordpicture matching task for lork (lion) could also have acted as a phonological or orthographic distracter. The category distracters for goak (guitar) and surn (sweets) also shared an initial phoneme/letter, but
} 
An adjusted semantic learning score was calculated to reflect overall sensitivity to semantic information. This score gave children credit for selecting targets in the specific condition and targets and category distracters in the general condition. Correlations showed that adjusted semantic learning scores were associated with reading accuracy (as measured during story reading and by independent standardized tests), reading comprehension, and existing oral vocabulary knowledge. Because semantic information was acquired through reading in this task, it is reasonable that reading accuracy correlated with semantic learning. However, once nonverbal reasoning had been controlled in hierarchical regressions, target decoding was not a unique predictor of semantic learning indicating that although self-teaching via phonological recoding supports orthographic learning, it did not make a substantial contribution to semantic learning. Regression analyses indicated that after controlling for the variance explained by nonverbal reasoning and target decoding, text reading accuracy, and oral vocabulary predicted unique variance in semantic learning. When the predictive power of these variables was contrasted, they explained similar amounts of variance, but oral vocabulary emerged as the stronger predictor. Therefore, the ability to understand individual words plays an important role in semantic learning (cf. Cain et al., 2004; Ewers \& Brownson, 1999; Sénéchal et al., 1995; Shefelbine, 1990).

There are a number of plausible explanations for a relationship between existing oral vocabulary skills and the ability to infer the meaning of new words from context. One possibility is that the relationship may be mediated by inference making and other comprehension processes (cf. Cain et al., 2004). However, in this study individual differences in reading comprehension did not explain significant variance in semantic learning after controlling for nonverbal reasoning and target decoding. Alternatively, there might be a more direct relationship. Plausibly, better vocabulary knowledge may indicate a more well-developed semantic system, which is somehow more able to encode new word meanings. The design of this experiment does not elucidate the exact mechanisms by which individual differences explain variance in semantic learning. Nonetheless, these findings indicate that children with poorer text reading skills and existing vocabulary knowledge are less likely to acquire the meanings of new words while reading, exacerbating their vocabulary difficulties over time.

This study highlights a number of methodological issues that should be considered in future research. Using the nonword-picture matching task as a measure of semantic learning introduced a potential confound; children selected a greater

there was no phonological or orthographic overlap between the remaining targets and their distracters. Inspection of the number of targets and category distracters selected in the general context condition for cases where there were or were not phonological/orthographic overlap between target nonword and category distracter did not reveal any evidence that this factor was driving the high selection of category distracters in the general context condition. 
number of category distracters than targets overall. If semantic learning had been assessed using another format (e.g., open-ended question: what is a lork?), then specific alternative responses, such as the category distracters, would not have been made salient by the semantic learning task. In other words, although children would still have made errors with another task, it is less likely that there would have been a preponderance to make the same error. In addition, our nonwords were paired with known objects rather than novel objects or concepts. Therefore, children were learning novel phonological and orthographic forms for easily nameable objects, a task akin to learning of synonyms or words in a second language. An important extension of this work would be to attempt to replicate our findings with a paradigm through which children learn novel semantic information. It may be that the predictors of individual differences in learning vary according to the type of learning task employed (cf. Cain et al., 2004).

In conclusion, our findings suggest that orthographic and semantic aspects of word learning are dissociable to the extent that they are predicted most strongly by different variables. Consistent with the self-teaching hypothesis (Share, 1995), target decoding was a strong predictor of orthographic learning. However, factors such as existing levels of orthographic knowledge may provide additional support for orthographic learning. In contrast, vocabulary did not predict orthographic learning, but this variable emerged as the strongest predictor of semantic learning. In addition, the correlations between semantic learning and orthographic learning were at best weak, indicating that these aspects of learning are separable. In light of the limitations previously described, future experiments should aim to extend this research by investigating both orthographic and semantic aspects of word learning in more transparent languages and in paradigms that elicit learning of truly novel concepts. Nonetheless, this work extends previous studies (e.g., Cain et al., 2003; Cain et al., 2004; Nation et al., 2007) by examining reading accuracy, reading comprehension, and existing vocabulary knowledge as predictors of both orthographic and semantic aspects of word learning in a large unselected group of English-speaking children aged 7 to 8 years.

\section{REFERENCES}

Allerup, P., \& Elbro, C. (1998). Comparing differences in accuracy across conditions or individuals: An argument for the use of log odds. Quarterly Journal of Experimental Psychology, 51A, 409-424.

Apel, K. (2009). The acquisition of mental orthographic representations for reading and spelling development. Communication Disorders Quarterly, 31, 42-52.

Apel, K., Wolter, J., \& Masterson, J. J. (2006). Effects of phonotactic and orthotactic probabilities during fast mapping on 5-year-olds' learning to spell. Developmental Neuropsychology, 29, 21-42.

Archer, N., \& Bryant, P. (2001). Investigating the role of context in learning to read: A direct test of Goodman's model. British Journal of Psychology, 92, 579-591. 
Beck, I., Perfetti, C., \& McKeown, M. (1982). Effects of long-term vocabulary instruction on lexical access and reading-comprehension. Journal of Educational Psychology, 74, 506-521.

Bowey, J. A., \& Miller, R. (2007). Correlates of orthographic learning in third-grade children's silent reading. Journal of Research in Reading, 30, 115-128.

Bowey, J. A., \& Muller, D. (2005). Phonological recoding and rapid orthographic learning in thirdgraders' silent reading: A critical test of the self-teaching hypothesis. Journal of Experimental Child Psychology, 92, 203-219.

Cain, K., Oakhill, J., \& Elbro, C. (2003). The ability to learn new word meanings from context by school-age children with and without language comprehension difficulties. Journal of Child Language, 30, 681-694.

Cain, K., Oakhill, J., \& Lemmon, K. (2004). Individual differences in the inference of word meanings from context: The influence of reading comprehension, vocabulary knowledge, and memory capacity. Journal of Educational Psychology, 96, 671-681.

Clay, F., Bowers, J. S., Davis, C. J., \& Hanley, D. A. (2007). Teaching adults new words: The role of practice and consolidation. Journal of Experimental Psychology: Learning, Memory, and Cognition, 33, 970-976.

Cunningham, A. E. (2006). Accounting for children's orthographic learning while reading text: Do children self-teach? Journal of Experimental Child Psychology, 95(1), 56-77.

Cunningham, A. E., Perry, K. E., Stanovich, K. E., \& Share, D. L. (2002). Orthographic learning during reading: Examining the role of self-teaching. Journal of Experimental Child Psychology, 82, 185-199.

Echols, L. D., West, R. F., Stanovich, K. E., \& Zehr, K. S. (1996). Using children's literacy activities to predict growth in verbal cognitive skills: A longitudinal investigation. Journal of Educational Psychology, 88, 296-304.

Ehri, L. C. (2005). Development of sight word reading: Phases and findings. In M. Snowling \& C. Hulme (Eds.), The science of reading: A handbook (pp. 135-154). Oxford, UK: Blackwell.

Ewers, C., \& Brownson, S. (1999). Kindergarteners' vocabulary acquisition as a function of active vs. passive storybook reading, prior vocabulary, and working memory. Reading Psychology, 20(1), 11-20.

Field, A. (2005). Discovering statistics using SPSS (2nd ed.). London, UK: Sage.

Hulme, C., Goetz, K., Gooch, D., Adams, J., \& Snowling, M. J. (2007). Paired-associate learning, phoneme awareness, and learning to read. Journal of Experimental Child Psychology, 96, 150-166.

Keenan, J. M., \& Betjemann, R. S. (2007). Comprehension of single words: The role of semantics in word identification and reading disability. In E. Grigorenko \& A. Naples (Eds.), Single-word reading: Behavioral and biological perspectives (pp. 191-210). Mahwah, NJ: Erlbaum.

Kyte, C. S., \& Johnson, C. J. (2006). The role of phonological recoding in orthographic learning. Journal of Experimental Child Psychology, 93, 166-185.

Landi, N., Perfetti, C. A., Bolger, D. J., Dunlap, S., \& Foorman, B. R. (2006). The role of discourse context in developing word form representations: A paradoxical relation between reading and learning. Journal of Experimental Child Psychology, 94, 114-133.

Masterson, J., Stuart, M., Dixon, M., \& Lovejoy, S. (2010). Children's printed word database: Continuities and changes over time in children's early reading vocabulary. British Journal of Psychology, 101, 221-242.

Nagy, W., Herman, P. A., \& Anderson, R. C. (1985). Learning words from context. Reading Research Quarterly, 20, 233-253.

Nation, K., Angell, P., \& Castles, A. (2007). Orthographic learning via self-teaching in children learning to read English: Effects of exposure, durability and context. Journal of Experimental Child Psychology, 96(1), 71-84.

Nation, K., \& Snowling, M. J. (1998). Individual differences in contextual facilitation: Evidence from dyslexia and poor reading comprehension. Child Development, 69, 996-1011. 
Nation, K., \& Snowling, M. J. (2004). Beyond phonological skills: Broader language skills contribute to the development of reading. Journal of Research in Reading, 27, 342-356.

Nation, K., Snowling, M. J., \& Clarke, P. (2007). Dissecting the relationship between language skills and learning to read: Semantic and phonological contributions to new vocabulary learning in children with poor reading comprehension. Advances in Speech-Language Pathology, 9, 131-139.

Neale, M. (1997). Neale Analysis of Reading Ability—Second revised British edition. Windsor, UK: NFER.

Oakhill, J. (1983). Instantiation in skilled and less skilled comprehenders. Quarterly Journal of Experimental Psychology, 35A, 441-450.

Ouellette, G., \& Beers, A. (2010). A not-so-simple view of reading: How oral vocabulary and visualword recognition complicate the story. Reading and Writing, 23, 189-208.

Ouellette, G., \& Fraser, J. R. (2009). What exactly is a yait anyway: The role of semantics in orthographic learning. Journal of Experimental Child Psychology, 104, 239-251.

Pacton, S., Perruchet, P., Fayol, M., \& Cleeremans, A. (2001). Implicit learning out of the lab: The case of orthographic regularities. Journal of Experimental Psychology: General, 130, 401-426.

Perfetti, C. A., \& Hart, L. (2002). The lexical quality hypothesis. In L. Verhoeven, C. Elbro, \& P. Reitsma (Eds.), Precursors of functional literacy (Vol. 11, pp. 189-213). Amsterdam, the Netherlands: John Benjamins.

Perfetti, C. A., Wlotko, E. W., \& Hart, L. A. (2005). Word learning and individual differences in word learning reflected in event-related potentials. Journal of Experimental Psychology: Learning, Memory, and Cognition, 31, 1281-1292.

Plaut, D. C., McClelland, J. L., Seidenberg, M., \& Patterson, K. (1996). Understanding normal and impaired word reading: Computational principles in quasi-regular domains. Psychological Review, $103,56-115$.

Rack, J., Hulme, C., Snowling, M., \& Wightman, J. (1994). The role of phonology in young children learning to read words: The direct-mapping hypothesis. Journal of Experimental Child Psychology, 57(1), 42-71.

Ricketts, J., Bishop, D. V. M., \& Nation, K. (2008). Investigating orthographic and semantic aspects of word learning in poor comprehenders. Journal of Research in Reading, 31(1), 117-135.

Ricketts, J., Bishop, D. V. M., \& Nation, K. (2009). Orthographic facilitation in oral vocabulary acquisition. Quarterly Journal of Experimental Psychology, 62, 1948-1966.

Rosenthal, J., \& Ehri, L. C. (2008). The mnemonic value of orthography for vocabulary learning. Journal of Educational Psychology, 100(1), 175-191.

Schneider, W., Eschman, A., \& Zuccolotto, A. (2002a). E-Prime reference guide. Pittsburgh, PA: Psychology Software Tools Inc.

Schneider, W., Eschman, A., \& Zuccolotto, A. (2002b). E-Prime user's guide. Pittsburgh, PA: Psychology Software Tools Inc.

Sénéchal, M., Thomas, E., \& Monker, J.-A. (1995). Individual differences in 4-year-old children's acquisition of vocabulary during storybook reading. Journal of Educational Psychology, 87, 218-229.

Share, D. L. (1995). Phonological recoding and self-teaching: Sine qua non of reading acquisition. Cognition, 55, 151-218.

Share, D. L. (1999). Phonological recoding and orthographic learning: A direct test of the self-teaching hypothesis. Journal of Experimental Child Psychology, 72, 95-129.

Share, D. L. (2008). On the anglocentricities of current reading research and practice: The perils of overreliance on an "outlier" orthography. Psychological Bulletin, 134, 584-615.

Shefelbine, J. L. (1990). Student factors related to variability in learning word meanings from context. Journal of Reading Behavior, 22(1), 71-97.

Stuart, M., Masterson, J., \& Dixon, M. (2000). Spongelike acquisition of sight vocabulary in beginning readers? Journal of Research in Reading, 23(1), 12-27. 
Swanborn, M., \& de Glopper, K. (2002). Impact of reading purpose on incidental word learning from context. Language Learning, 52(1), 95-117.

Torgesen, J., Wagner, R., \& Rashotte, C. (1999). Test of Word Reading Efficiency. Austin, TX: Pro-Ed. Wechsler, D. (1999). Wechsler Abbreviated Scale of Intelligence. London, UK: The Psychological Corporation.

Wright, D. M., \& Ehri, L. C. (2007). Beginners remember orthography when they learn to read words: The case of doubled letters. Applied Psycholinguistics, 28, 115-133. 


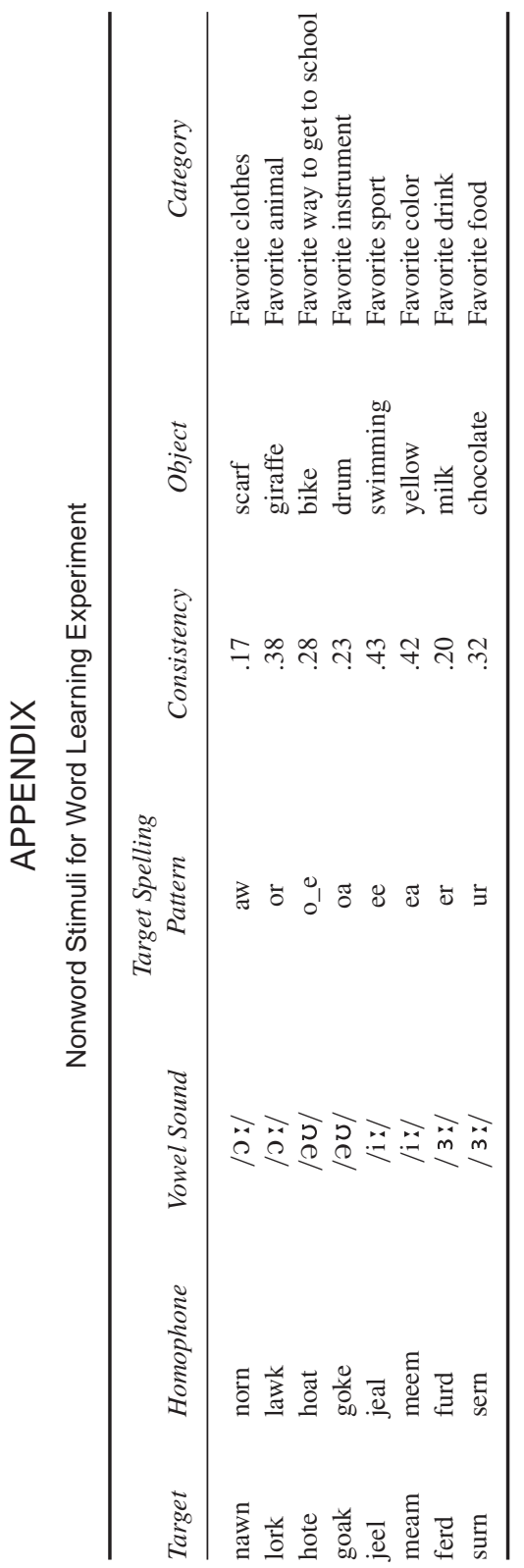

